\title{
Potential repositioning of GV1001 as a therapeutic agent for testosterone-induced benign prostatic hyperplasia
}

\author{
KYEONG SEOK KIM ${ }^{1}$, HUN YONG YANG ${ }^{1}$, SEUNG-CHEOL CHANG ${ }^{2}$, \\ YOUNG-MI KIM ${ }^{3}$, KWANG YOUL LEE ${ }^{4}$, BYUNG MU LEE ${ }^{1}$ and HYUNG SIK KIM ${ }^{1}$ \\ ${ }^{1}$ Department of Toxicology, School of Pharmacy, Sungkyunkwan University, Suwon, Gyeonggi-do 16419; \\ ${ }^{2}$ Institute of Bio-Physio Sensor Technology, Center for Proteome Biophysics, Pusan National University, Busan 46241; \\ ${ }^{3}$ College of Pharmacy and Institute of Pharmaceutical Science and Technology, Hanyang University, \\ Ansan, Gyeonggi-do 15588; ${ }^{4}$ College of Pharmacy and Research Institute of Drug Development, \\ Chonnam National University, Gwangju, Gwangju 61186, Republic of Korea
}

Received March 12, 2018; Accepted June 18, 2018

DOI: $10.3892 /$ ijmm.2018.3759

\begin{abstract}
Benign prostatic hyperplasia (BPH) is one of the leading causes of male reproductive disorders. Therapeutic agents currently in use have severe side effects; therefore, alternative drugs that exhibit improved therapeutic activity without side effects are required. The present study investigated the protective effect of GV1001 against testosterone-induced BPH in rats. BPH in castrated rats was established via daily subcutaneous (s.c.) injections of testosterone propionate (TP, $3 \mathrm{mg} / \mathrm{kg})$ dissolved in corn oil for 4 weeks. GV1001 (0.01, 0.1 and $1 \mathrm{mg} / \mathrm{kg}$, s.c.) was administered 3 times per week for 4 weeks, together with TP $(3 \mathrm{mg} / \mathrm{kg})$ injection. The rats were sacrificed on the last day of treatment, and their prostates were excised and weighed for biochemical and histological studies. Serum levels of testosterone and dihydrotestosterone (DHT) were also measured. In rats with TP-induced BPH, a significant increase in prostate weight (PW) and prostatic index (PI), accompanied by a decrease in antioxidant enzyme activity, was observed. Histological studies revealed clearly enlarged glandular cavities in rats with BPH. GV1001 (0.01 and $0.1 \mathrm{mg} / \mathrm{kg}$ ) treatment significantly decreased PW and PI in rats with TP-induced BPH. In addition, GV1001 demonstrated a potent inhibitory effect on $5 \alpha$-reductase in prostate. The present data suggest that the protective role of GV1001 against testosterone-induced BPH is closely associated with its antioxidant potential. Additional studies are required to identify the mechanisms by which GV1001 protects against BPH to determine its clinical application.
\end{abstract}

Correspondence to: Professor Hyung Sik Kim, Department of Toxicology, School of Pharmacy, Sungkyunkwan University, 2066 Seobu-ro, Suwon, Gyeonggi-do 440-746, Republic of Korea E-mail: hkims@skku.edu

Key words: GV1001, benign prostate hyperplasia, antioxidants, $5 \alpha$-reductase

\section{Introduction}

Benign prostatic hyperplasia (BPH) is the most common prostate disease in elderly men and affects nearly one-half of all men aged $>50$ years (1-3). Previous studies have demonstrated that an imbalance between androgens and estrogens serves an important role in the development and progression of BPH $(4,5)$. The growth and enlargement of prostatic tissue are dependent on androgenic stimulation by the potent androgenic receptor agonist dihydrotestosterone (DHT), which is generated by the conversion of testosterone by the $5 \alpha$-reductase enzyme. Therefore, $5 \alpha$-reductase inhibitors (finasteride and dutasteride) or $\alpha 1$-adrenergic blockers are typically used for clinical management of BPH $(5,6)$. However, these drugs incur side effects including impotence, ejaculatory dysfunction, painful ejaculation, decreased libido, dizziness, headache and fatigue (7-9). Furthermore, post-marketing studies clearly suggested that certain patients exhibited side effects including rashes, tachycardia and chest pain (10).

Although there has been much effort during the previous decade to gain insight into the etiology of BPH, a detailed understanding of the pathophysiological processes is lacking. DHT increases the mitochondrial activity in prostatic cells, resulting in excessive free radical formation and oxidative damage to the prostate (11). This oxidative stress is caused by an imbalance between the production and scavenging of free radicals in the system, resulting in damage to cellular components. Data suggest that oxidative stress is associated with BPH (12), and various studies have indicated the role of oxidative stress in either the initiation or the progression of BPH (13-15). Augmenting the function of antioxidants and redox systems against oxidative stress in male reproductive tissues has been previously described, and a number of types of antioxidants may prevent BPH development induced by oxidative stress (13). Vitamin E, selenium, diallyl sulfide and black tea extract have been demonstrated to significantly modulate testosterone-induced oxidative stress due to their antioxidant potential (14-16). Therefore, the use of exogenous antioxidant therapy may be protective in BPH.

GV1001 is a 16-amino acid hTERT peptide that was selected based on computer algorithms predicting strong HLA 
class II binding properties and multiple nested HLA class I binding motifs $(17,18)$. GV1001 was first developed as a chemotherapeutic drug for the treatment of various types of cancer, including advanced pancreatic cancer, melanoma, non-small cell lung cancer, advanced hepatocellular carcinoma and prostate cancer (19-22). Previous studies have suggested that GV1001 also exerts a protective effect against ischemia-reperfusion injury through antioxidant effects, by reducing reactive oxygen species (ROS) and suppressing the inflammatory cascade (23). GV1001 exhibits neuroprotective effects in neural stem cells following treatment with $\mathrm{H}_{2} \mathrm{O}_{2}$ that appear to be mediated by the scavenging of free radicals, increased survival signals and decreased death signals (24). GV1001 exhibited anti-inflammatory activity in LPS-stimulated pulpitis without significantly affecting cell viability (25). Although the pharmacological activities of GV1001 have been extensively investigated with regard to its anti-inflammatory, antipyretic and antioxidant activities $(23,26)$, to the best of our knowledge there have been no studies evaluating the effect of GV1001 in testosterone-induced BPH. In particular, the mechanisms by which GV1001 regulate steroid hormone synthesis have not yet been elucidated.

The present study investigated whether GV1001 protected rats from testosterone-induced BPH and explored the protective mechanism of GV1001 in a model of testosterone-induced BPH in castrated rats. The results revealed that GV1001 injection significantly inhibited a testosterone-mediated increase in prostate weight and relative prostate weight. Therefore, the results of the present study may be used to support future clinical applications of GV1001 in BPH prevention or therapy.

\section{Materials and methods}

Materials. GV1001 was kindly provided by GemVax \& KAEL (Seongnam, South Korea). Finasteride, testosterone propionate (TP) and all other reagents used in the present study were purchased from Sigma Aldrich; Merck KGaA (Darmstadt, Germany). Assay kits for glutathione (GSH), SOD, CAT and MDA were purchased from Abcam (Cambridge, MA, USA). All other assay kits were purchased from Cayman Chemical Company (Ann Arbor, MI, USA).

Castration procedures and experimental animal model. Specific pathogen-free male Sprague-Dawley rats aged 10 weeks $(n=42 ; 280 \pm 5 \mathrm{~g})$ that were routinely screened serologically for relevant respiratory pathogens were purchased from Central Lab. Animal, Inc. (Seoul, Korea). The rats were maintained in an animal facility under standard laboratory conditions for 1 week prior to the experiments and subjected to a $12 \mathrm{~h}$ light-dark cycle in a room with controlled temperature $\left(22 \pm 1^{\circ} \mathrm{C}\right)$ and humidity $(55 \pm 10 \%)$, as well as free access to rodent chow and tap water. All experimental procedures were performed in accordance with the Korea Food and Drug Administration (FDA) Guidelines for the Care and Use of Laboratory Animals, and animal handling followed the dictates of the National Animal Welfare Law of Korea. After 1 week of acclimation, the rats were randomly distributed into experimental groups. All experimental procedures were performed in accordance with guidelines of the Committee for the Purpose of Control and Supervision of Experiments on Animals of Sungkyunkwan University. The present study was reviewed and approved by the Sungkyunkwan University Animal Ethics Committee.

To exclude the effect of intrinsic testosterone, castration was performed in all rats by removing the testes and epididymis through the scrotal sac. BPH was induced in rats by subcutaneous (s.c.) injections of TP $(3 \mathrm{mg} / \mathrm{kg})$ for 4 weeks following castration $(27,28)$. Castrated rats were divided into six groups ( $\mathrm{n}=6$ for each): Group 1, the castration group, which received corn oil s.c.; Group 2, the BPH group, which received TP (3 mg/kg) s.c.; Groups 3-5, the GV1001 groups, which received GV1001 $(0.01,0.1$ or $1 \mathrm{mg} / \mathrm{kg})$ and $\mathrm{TP}(3 \mathrm{mg} / \mathrm{kg})$ s.c.; Group 6, the positive control group, which received finasteride $(10 \mathrm{mg} / \mathrm{kg})$ orally and TP $(3 \mathrm{mg} / \mathrm{kg})$ s.c. for 4 weeks following castration. Animals from all groups were examined every other day for morphological changes, and body weight (BW) was measured. The dosage of GV1001 was based on data from our previous dose-escalation study in patients with pancreatic cancer without toxicity (18). Subsequent to a treatment period of 4 weeks and overnight fasting, the rats were anesthetized with tribromoethanol $(250 \mathrm{mg} / \mathrm{kg} \mathrm{BW}$, i.p.). Blood samples were collected and centrifuged at $300 \mathrm{x} \mathrm{g}$ for $10 \mathrm{~min}$ at $4^{\circ} \mathrm{C}$. Prostate and seminal vesicles from each animal were excised, weighed and immediately washed with ice-cold saline. A part of the ventral lobe of the prostate was stored in neutral buffered formalin for the histological studies, and the remainder of the prostate was used for the biochemical assays. A $2 \%$ tissue homogenate was prepared in ice-cold phosphate buffer containing $0.15 \mathrm{M} \mathrm{KCl}$ for use as the enzyme source.

Prostatic index (PI) and percent inhibition. The PI was determined as the ratio of prostate weight (PW) to BW of each rat using the formula: PW/BW. After 4 weeks, each rat was weighed and then sacrificed by cervical dislocation. The prostates were removed and weighed immediately. Percent inhibition was calculated as 100-[(treated group-negative control)/(positive control-negative control) x100].

Histopathological examination. All prostate specimens from each group were fixed with $10 \%$ neutral-buffered formalin for $24 \mathrm{~h}$ at room temperature. To assess morphological changes in the prostate, tissues were embedded in paraffin, cut into $4-\mu \mathrm{m}$ thick sections, and stained with hematoxylin and eosin for $1 \mathrm{~min}$ at room temperature. Tissues were subsequently mounted and cover-slipped using mounting medium (Invitrogen; Thermo Fisher Scientific, Inc., Waltham, MA, USA), and then examined by light microscopy (Nikon Corporation, Tokyo, Japan). The prostatic epithelial height $(\mu \mathrm{m})$ was measured by manually drawing a line through the acinar epithelia [30 measures/field (20 fields in total)]. The acinar luminar area $\left(\mu \mathrm{m}^{2}\right)$ was measured by drawing a line around the luminar perimeter and calculating the acinar area.

Measurement of testosterone and DHT in the prostate. For protein extraction, prostate tissues were washed once with PBS and resuspended in lysis buffer $(\mathrm{pH} 8.0,50 \mathrm{mM}$ Tris, $150 \mathrm{mM}$ $\mathrm{NaCl}, 5 \mathrm{mM}$ EDTA, 1\% NP-40, 0.1\% SDS and $1 \mathrm{mM}$ phenylmethane sulfonyl fluoride). The homogenates were centrifuged at $12,000 \times \mathrm{g}$ for $25 \mathrm{~min}$ at $4^{\circ} \mathrm{C}$, and protein concentration in the supernatant fractions was determined using a Bradford 
Table I. Effect of GV1001 and finasteride on BW, PW and PI of rats with benign prostate hyperplasia.

\begin{tabular}{lcccccc}
\hline & \multicolumn{2}{c}{ Body weight $(\mathrm{g})$} & & \\
\cline { 3 - 6 } Treatment groups & Dose,$(\mathrm{mg} / \mathrm{kg})$ & Initial & Final & PW, $\mathrm{mg}$ & PI $(\mathrm{mg} / \mathrm{g})$ & Inhibition $\%$ \\
\hline Vehicle control & 0 & $287.9 \pm 3.97$ & $351.4 \pm 8.81$ & $14.5 \pm 4.62$ & 0.04 & - \\
BPH model & 0 & $293.5 \pm 3.86$ & $381.1 \pm 5.37$ & $242.8 \pm 36.53$ & 0.63 & - \\
GV1001 & 0.01 & $322.0 \pm 5.32$ & $400.8 \pm 10.1$ & $141.4 \pm 10.92^{\mathrm{a}}$ & $0.35^{\mathrm{a}}$ & $47.4^{\mathrm{a}}$ \\
GV1001 & 0.1 & $328.3 \pm 8.26$ & $399.5 \pm 11.1$ & $63.6 \pm 11.1^{\mathrm{b}}$ & $0.15^{\mathrm{b}}$ & $81.3^{\mathrm{b}}$ \\
GV1001 & 1 & $330.3 \pm 5.01$ & $404.3 \pm 13.4$ & $224.4 \pm 25.31$ & 0.55 & 13.6 \\
Finasteride & 10 & $293.3 \pm 9.41$ & $389.7 \pm 17.8$ & $93.6 \pm 12.35^{\mathrm{b}}$ & $0.24^{\mathrm{b}}$ & $66.1^{\mathrm{b}}$ \\
\hline
\end{tabular}

All data are presented as mean \pm standard deviation of 6 experimental animals. ${ }^{\mathrm{a}} \mathrm{P}<0.05$ and ${ }^{\mathrm{b}} \mathrm{P}<0.01 \mathrm{vs}$. BPH group. PI, PW (mg)/BW (g). BW, body weight; PW, prostate weight; PI, prostatic index.

reagent (Bio-Rad Laboratories, Inc., Hercules, CA, USA). Testosterone (cat. no. 582701; Cayman Chemical Company) and DHT (cat. no. 11-DHTHU-E01; ALPCO, Salem, NH, USA) levels were measured using ELISA kits according to their corresponding manufacturer's protocol. The values were expressed per ng or pg per mg protein in the prostate.

Assay for $5 \alpha$-reductase enzyme activity. The dorsolateral prostate $(100 \mathrm{mg})$ was homogenized in $1 \mathrm{ml}$ of $40 \mathrm{mM}$ sodium phosphate buffer ( $\mathrm{pH}$ 6.5) containing sucrose and DTT $(1 \mathrm{mM})$ in $1 \mathrm{X}$ PBS. The homogenate was centrifuged at 5,000 $\mathrm{x} \mathrm{g}$ for $10 \mathrm{~min}$ at $4^{\circ} \mathrm{C}$. The supernatant was further centrifuged for $1 \mathrm{~h}$ at $10,500 \mathrm{x} g$ at $4^{\circ} \mathrm{C}$. The resulting precipitate was resuspended in $1 \mathrm{ml} 40 \mathrm{mM}$ sodium phosphate buffer ( $\mathrm{pH}$ 7.4) containing sucrose $(0.3 \mathrm{M})$ and DTT $(1 \mathrm{mM})$. This was used as the enzyme source, as previously described (29). The protein content in the supernatant fractions was determined using a Bio-Rad Protein Assay kit (Bio-Rad Laboratories, Inc.). Each enzyme reaction was conducted in duplicate. The activity of enzyme was evaluated with SRD5 $\alpha 1$ ELISA detection kit (cat. no. MBS700746) according to the manufacturer's protocol (Biocompare, San Francisco, CA, USA). Absorbance was measured at $450 \mathrm{~nm}$ with a microplate reader. The concentration of SRD5 $\alpha 1$ in the samples was subsequently determined by comparing the optical density of the samples to the standard curve.

Assay for antioxidant enzymes. Prostate tissue was homogenized $(1 / 10 \mathrm{w} / \mathrm{v})$ in tissue lysis/extraction reagent containing protease inhibitors. Homogenates were centrifuged at $12,000 \mathrm{x} \mathrm{g}$ for $25 \mathrm{~min}$ at $4^{\circ} \mathrm{C}$. The protein content in the supernatant fractions was determined using a Bio-Rad Protein Assay kit (Bio-Rad Laboratories, Inc.). The activities of superoxide dismutase (SOD; cat. no. ab65353) and catalase (CAT; cat. no. ab118184) and GSH (cat. no. ab65322) levels were quantified using commercial kits according to the manufacturer's protocols (Abcam), and the results were expressed as $\mathrm{U} / \mathrm{mg}$ protein, as described previously (30).

Lipid peroxidation assay. Concentration of malondialdehyde (MDA), an index of lipid peroxidation, was determined based on thiobarbituric acid reactive species production. MDA concentrations were calculated using a TBARS Assay kit (cat. no. KGE013) according to the manufacturer's protocol (R\&D Systems, Inc., Minneapolis, MN, USA) and normalized to protein levels. In brief, equal volumes (100 $\mu \mathrm{l})$ sample and SDS were added to a $5 \mathrm{ml}$ conical vial. Following vortexing, samples were mixed with $0.4 \mathrm{ml}$ of $1 \%$ thiobarbituric acid in $50 \mathrm{~mm} \mathrm{NaOH}$ and $0.2 \mathrm{ml}(20 \%) \mathrm{H}_{3} \mathrm{PO}_{4}$. The mixture was heated to $100^{\circ} \mathrm{C}$ for $15 \mathrm{~min}$. After $10 \mathrm{~min}$ incubation on ice, vials were centrifuged at $1,600 \mathrm{x}$ for $10 \mathrm{~min}$ at $4^{\circ} \mathrm{C}$. The samples $(100 \mu \mathrm{l})$ were loaded onto 96 -well assay plates, and the absorbance of each well was measured at a wavelength of $540 \mathrm{~nm}$ using a microplate reader.

Evaluation of apoptosis in prostate tissues. Apoptosis in the prostate tissues was evaluated using a terminal deoxynucleotidyl-transferase-mediated dUTP nick end labelling (TUNEL) assay. Cell apoptosis was analyzed using an in situ cell death-detection kit (Promega Corporation, Madison, WI, USA) according to the manufacturer's protocol. Slides were de-waxed with $100 \%$ xylene and rehydrated with pure ethanol. The slides were fixed overnight at room temperature in $100 \mathrm{~g} / \mathrm{l}$ formaldehyde, treated with proteinase $\mathrm{K}$ and $\mathrm{H}_{2} \mathrm{O}_{2}$ and labeled with dUTP in a humidified chamber at $37^{\circ} \mathrm{C}$ for $1 \mathrm{~h}$. TUNEL-positive cell number was counted in 10 fields of view in each slide. Images were captured using a confocal microscope (magnification, x50; LSM510; Carl Zeiss AG, Oberkochen, Germany).

Statistical analysis. Statistical analyses were performed with GraphPad Prism software v5.03 (GraphPad Software, Inc., La Jolla, CA, USA). All numerical data are presented as mean \pm standard deviation. $\mathrm{P}<0.05$ and $\mathrm{P}<0.01$ were considered to indicate a statistically significant difference. Statistical analyses were performed using Student's t-test or Mann-Whitney U test. One-way analysis of variance with Tukey's post hoc test was used for comparison among multiple groups.

\section{Results}

Effects of GV1001 on BW changes and clinical signs. There were no significant differences in BW between BPH rats treated with vehicle control or GV1001 (Table I). 

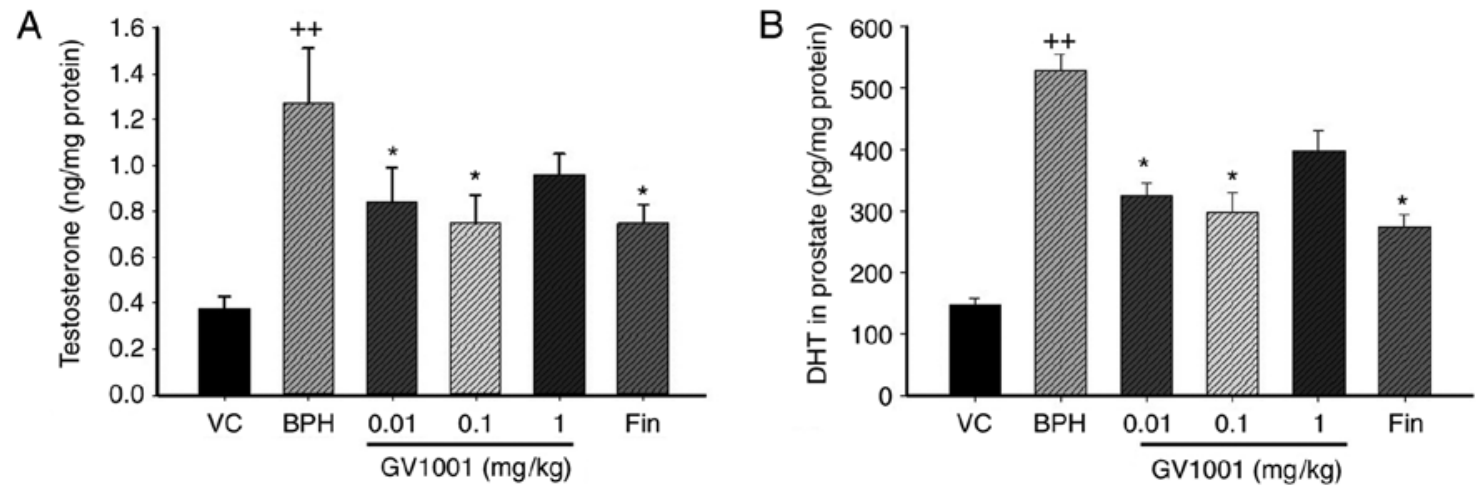

Figure 1. Effect of GV1001 on testosterone and dihydrotestosterone (DHT) concentrations in prostate tissues. (A) Testosterone and (B) DHT concentrations were measured in prostate homogenates. s.c., subcutaneous; TP, testosterone propionate; VC, vehicle control; BPH, benign prostatic hyperplasia; Fin, oral administration of finasteride $(10 \mathrm{mg} / \mathrm{kg})$ and s.c. injection of $3 \mathrm{mg} / \mathrm{kg}$ TP. Values are presented as mean \pm standard deviation $(\mathrm{n}=6)$. ${ }^{*} \mathrm{P}<0.05$ vs. the BPH group and ${ }^{++} \mathrm{P}<0.01$ vs. the $\mathrm{VC}$ group.
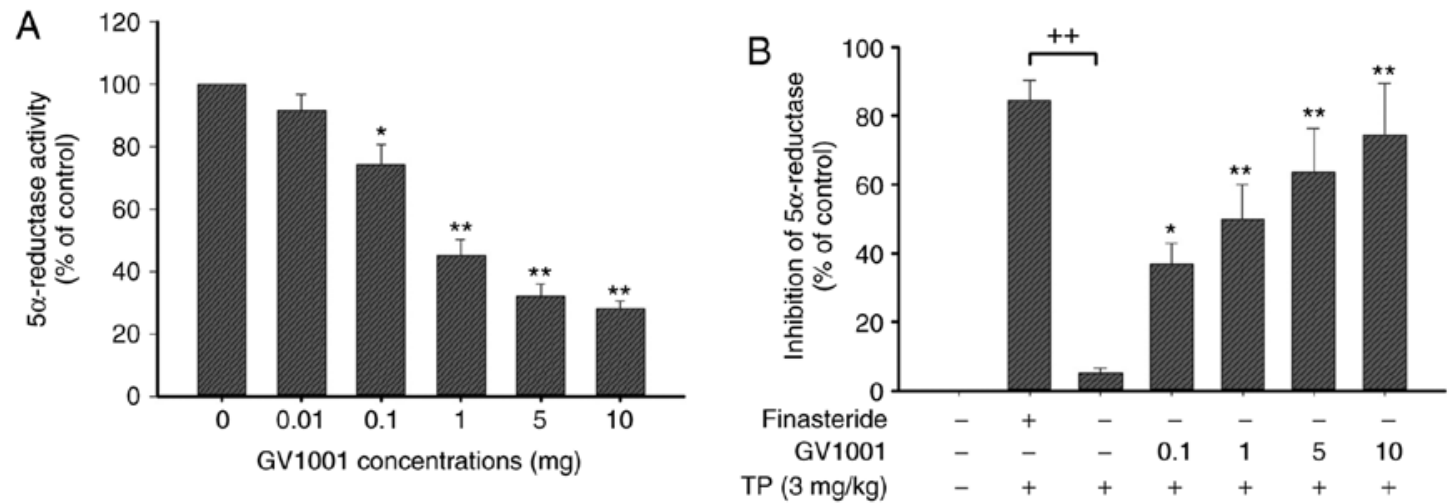

Figure 2. Effect of GV1001 on $5 \alpha$-reductase enzyme activity in the prostate. (A) $5 \alpha$-Reductase activity was measured using rat dorsolateral prostate treated with GV1001. All data are presented as mean \pm SD of duplicate experiments. ${ }^{P}<<0.05$ and ${ }^{* *} \mathrm{P}<0.01$ vs. the vehicle control group. (B) Enzyme activity was measured using prostate homogenate. Inhibitory activity (\% of control) against $5 \alpha$-reductase was determined using an ELISA assay kit. All data are presented as mean $\pm \mathrm{SD}$ of duplicate experiments $(\mathrm{n}=6) .{ }^{++} \mathrm{P}<0.01$ vs. the $\mathrm{VC}$ group, and ${ }^{*} \mathrm{P}<0.05$ and ${ }^{* *} \mathrm{P}<0.01$ vs. the $\mathrm{BPH}(\mathrm{TP}, 3 \mathrm{mg} / \mathrm{kg})$ group. SD, standard deviation; $\mathrm{TP}$, testosterone propionate. $\mathrm{BPH}$, benign prostate hyperplasia.

Effects of GV1001 on PW and PI. Animals treated with TP exhibited significant increases in PW and PW:BW ratio compared with animals treated with vehicle. Compared with the TP-induced BPH rats, rats treated with 0.01 and $0.1 \mathrm{mg} / \mathrm{kg}$ s.c. GV1001 exhibited significantly decreased PW, by 41.73 and $73.7 \%$, respectively. Similarly, 0.01 and $0.1 \mathrm{mg} / \mathrm{kg} \mathrm{GV1001}$ treatment significantly decreased PI to 0.35 and 0.15 , respectively, compared with TP treatment $(\mathrm{P}<0.01)$. However, these effects were not dose-dependent, as the high dose $(1 \mathrm{mg} / \mathrm{kg})$ of GV1001 did not significantly decrease PW and PI, compared with the BPH group (Table I). As a positive control, finasteride $(10 \mathrm{mg} / \mathrm{kg}$, orally) markedly decreased PW and PI to 61.4 and $66.1 \%$, respectively, compared with vehicle treatment (Table I).

Effects of GV1001 on the levels of testosterone and DHT in prostate. The major prostatic androgen is DHT, which is formed from testosterone by the $5 \alpha$-reductase enzyme (6,31). Significantly increased levels of testosterone were identified in rats of the TP-induced BPH group $(1.36 \pm 0.07 \mathrm{ng} / \mathrm{mg}$ protein) compared with the vehicle control group $(0.38 \pm 0.17 \mathrm{ng} / \mathrm{mg}$ protein; $\mathrm{P}<0.01 ;$ Fig. $1 \mathrm{~A})$. By contrast, rats in the finasteride-treated group $(0.78 \pm 0.14 \mathrm{ng} / \mathrm{mg}$ protein) showed significantly decreased testosterone levels compared with those in the BPH group $(\mathrm{P}<0.05)$. Similarly, rats in the GV1001 $(0.1 \mathrm{mg} / \mathrm{kg})$-treated group $(0.76 \pm 0.18 \mathrm{ng} / \mathrm{mg}$ protein $)$ indicated a marked decrease in testosterone levels compared with those of the BPH group.

The DHT level in the prostate of BPH rats was markedly increased compared with that in vehicle control rats $(524.24 \pm 78.69$ vs. $149.09 \pm 12.60 \mathrm{pg} / \mathrm{mg}$ protein). However, the prostatic DHT level in the finasteride-treated group $(267.43 \pm 29.63 \mathrm{pg} / \mathrm{mg}$ protein) was significantly decreased compared with that of the BPH-treated group. The level of prostatic DHT in the GV1001 $(0.1 \mathrm{mg} / \mathrm{kg})$-treated group $(297.17 \pm 43.05 \mathrm{pg} / \mathrm{mg}$ protein; $\mathrm{P}<0.05)$ was also markedly decreased compared with that of BPH rats (Fig. 1B).

Effects of GV1001 on 5 $\alpha$-reductase activity. To compare the inhibitory activity of GV1001, an enzyme assay was performed using finasteride (steroidal positive control) against an enzyme suspension of $5 \alpha$-reductase prepared from prostates of rats. This assay exhibited high sensitivity and excellent specificity for the detection of human SRD5A2 (Fig. 2A). As demonstrated in Fig. 2B, GV1001 exhibited a dose-dependent inhibitory activity (GV1001 $1 \mathrm{mg}, 40.5 \pm 5.2 \%$ inhibition), whereas finasteride positive controls indicated potent inhibition. 
A a vc

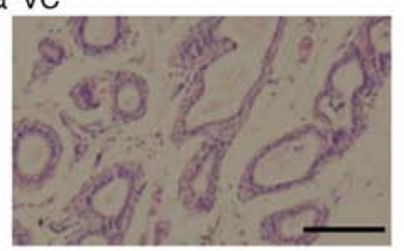

C BPH+GV1001 (0.01 mg/kg)

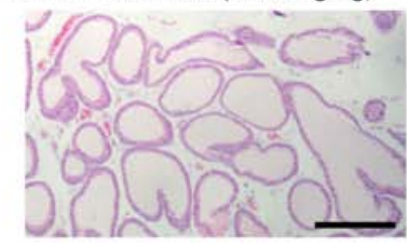

e BPH+GV1001 (1 mg/kg)

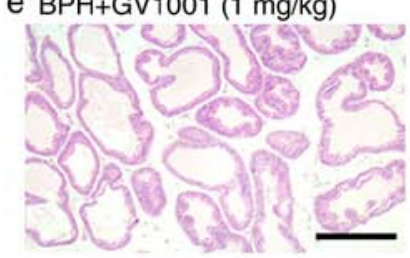

b $\mathrm{BPH}(\mathrm{TP}, 3 \mathrm{mg} / \mathrm{kg})$

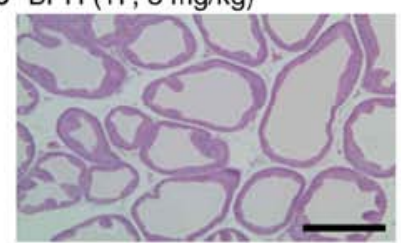

d BPH+GV1001 $(0.1 \mathrm{mg} / \mathrm{kg})$

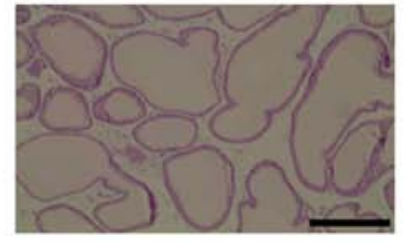

f $B P H+F i n(10 \mathrm{mg} / \mathrm{kg})$

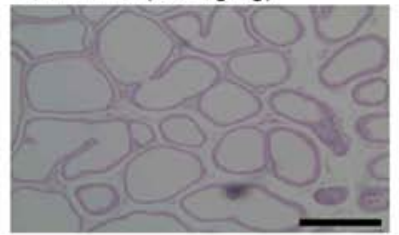

B

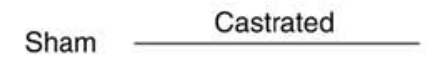

$\mathrm{TP}(3 \mathrm{mg} / \mathrm{kg})$

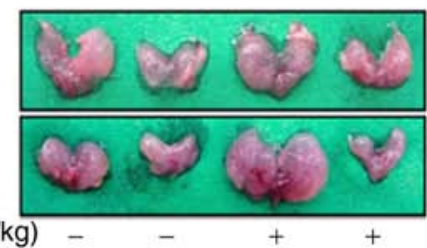

GV1001 $(0.01 \mathrm{mg} / \mathrm{kg}) \quad-\quad \ldots \quad-\quad+$

C

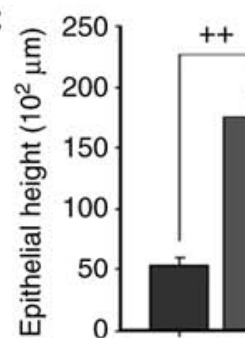

TP (3 mg/kg)

GV1001 (mg/kg)

Finasteride $(\mathrm{mg} / \mathrm{kg})$

Figure 3. Effects of GV1001 on benign prostate hyperplasia. (A) Histological examination of prostate tissue was performed $24 \mathrm{~h}$ after the final TP injection. Prostate tissues were fixed, sectioned at $4 \mu \mathrm{m}$ thickness and stained with hematoxylin $\&$ eosin solution. Scale bars $=100 \mu \mathrm{m}$. (a) Castration: Corn oil injection (s.c.) + oral administration of PBS; (b) BPH: TP (3 mg/kg, s.c.) injection; (c) GV1001 injection (0.01 mg/kg, s.c.) of + TP (3 mg/kg) injection; (d) GV1001 injection $(0.1 \mathrm{mg} / \mathrm{kg}$, s.c.) of + TP $(3 \mathrm{mg} / \mathrm{kg})$ injection; (e) GV1001 injection $(1 \mathrm{mg} / \mathrm{kg}$, s.c.) of + TP $(3 \mathrm{mg} / \mathrm{kg})$ injection; (f) oral administration of finasteride $(10 \mathrm{mg} \mathrm{kg} / \mathrm{kg}$, Fin) + TP injection. GV1001 or finasteride (Fin) treatment was performed $1 \mathrm{~h}$ prior to TP injection. BPH, benign prostate hyperplasia. (B) Effects of GV1001 on prostate size. The rat model of BPH was generated by injection of TP for 4 weeks after castration. Castration involved corn oil injection (s.c.) + oral administration of PBS; BPH treatment involved TP (s.c.) injection + oral administration of PBS; GV1001 treatment [injection of GV1001 (0.01 mg/kg) + $\mathrm{TP}(3 \mathrm{mg} / \mathrm{kg}$, s.c.) injection] was performed $1 \mathrm{~h}$ prior to TP injection. (C) Effect of GV1001 on proliferation of columnar epithelial cells. Values are presented as mean \pm standard deviation. ${ }^{++} \mathrm{P}<0.01$ vs. vehicle control group and ${ }^{*} \mathrm{P}<0.05$ vs. $\mathrm{BPH}$ group $(\mathrm{TP}, 3 \mathrm{mg} / \mathrm{kg}$ ). BPH, benign prostate hyperplasia; Fin, finasteride; $\mathrm{TP}$, testosterone propionate; s.c., subcutaneous.

Effect of GV1001 on prostate histopathological examination. Sections from the control group demonstrated normal histological architecture of the prostate (Fig. 3A). The tissues were tightly packed with flattened cuboidal regular sized epithelium with a regular acinar folding arrangement. In BPH rats, irregular acinar folding with intraluminar projections, hemorrhage, cystic spaces and nuclear conglomerates with marked hyperplasia, congestion and vacuolation were observed as evidence of disruption of the histoarchitecture (Fig. 3A-a). The prostates from the TP-treated group also exhibited luminal epithelial hyperplasia with intraluminal polyps and engorged blood vessels (Fig. 3A-b). Co-treatment with GV1001 (0.01 and $0.1 \mathrm{mg} / \mathrm{kg})$ attenuated the pathological alterations induced by testosterone (Fig. 3A-c and A-d). These effects were similar to those observed in the finasteride-treatment group (Fig. 3A-f). Treatment with finasteride also resulted in regular unfolded acini. However, these histopathological data did not reveal a dose-dependent restoration of the histoarchitecture (Fig. 3A-e). Fig. 3B indicates the representative prostate size following GV1001 treatment in BPH rats. Injection of TP increased the epithelial height of the prostate to $175 \times 10^{2} \mu \mathrm{m}$ compared with that of vehicle control rats. However, treatment with GV1001 at $0.01 \mathrm{mg} / \mathrm{kg}$ significantly decreased epithelial height to $75.5 \times 10^{2} \mu \mathrm{m}$, compared with that of $\mathrm{BPH}$ rats $(\mathrm{P}<0.05)$. Finasteride also significantly decreased the prostatic epithelial height to $61.5 \times 10^{2} \mu \mathrm{m}$ compared with BPH (Fig. 3C).

Effect of GV1001 on prostatic antioxidant enzyme activity. In $\mathrm{BPH}$ rats, the activities of SOD and CAT and the level of GSH were significantly $(\mathrm{P}<0.01)$ decreased by $65.6,68$ and $85.95 \%$ of vehicle control-treated rats. By contrast, GV1001 $0.1 \mathrm{mg} / \mathrm{kg}$ significantly restored SOD and CAT activity and GSH levels by $87.7,75.8$ and $79.3 \%$, respectively, compared with vehicle control. Finasteride also significantly restored SOD, CAT and GSH by $85.8,79.01$ and $84 \%$, respectively, compared with the vehicle control (Fig. 4).

Effect of GV1001 on prostatic lipid peroxides. To investigate the effect of GV1001 on oxidative stress in BPH, the concentration of MDA, an indicator of lipid peroxidation, in the prostate was measured. MDA concentration was significantly increased in the TP-induced BPH group compared with the vehicle control group, as previously described (32) (Fig. 4D). By contrast, MDA concentration was significantly decreased in the $0.1 \mathrm{mg} / \mathrm{kg}$-treated GV1001 group and the finasteride-treated group compared with the TP-induced BPH group. These data suggest that GV1001 injection prevented BPH by protecting the prostate from oxidative stress.

GV1001 induces apoptosis in prostate tissues. To determine whether the inhibitory effect of GV1001 on prostate growth was due to the apoptotic cell death pathway, the effect of GV1001 on apoptosis in BPH rats was measured by immunohistochemical staining using TUNEL. The number of TUNEL-positive cells in the control group was $13.21 \pm 1.57$, and that in the prostatic hyperplasia-induced group was $1.25 \pm 0.54$. The numbers of positive cells in the $0.01,0.1$ and 
A
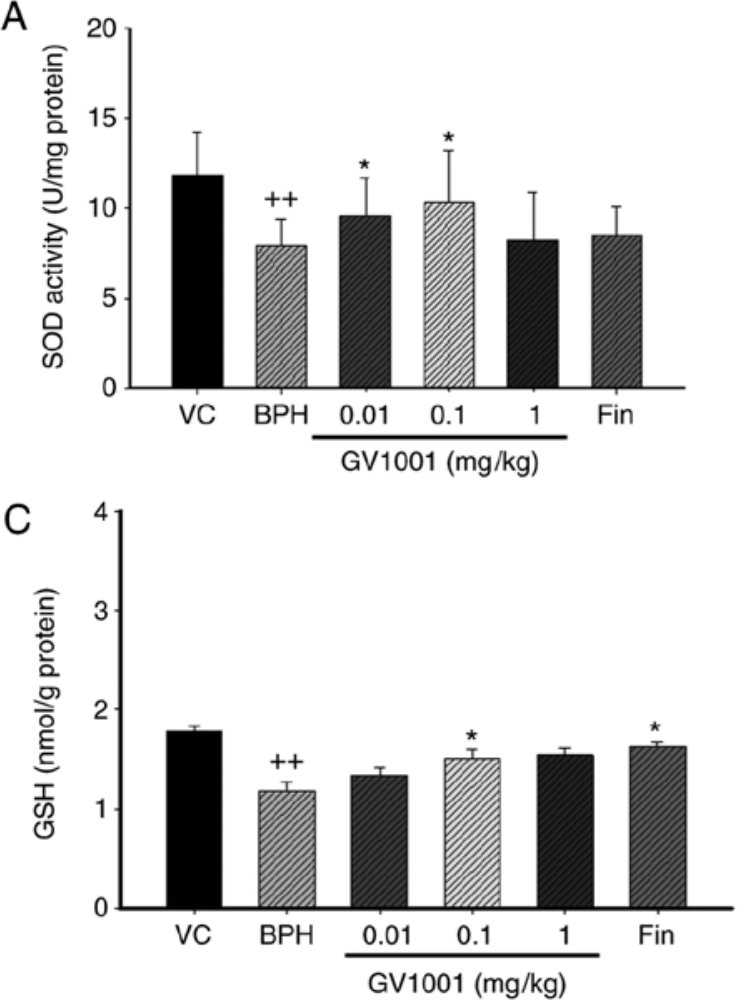

B

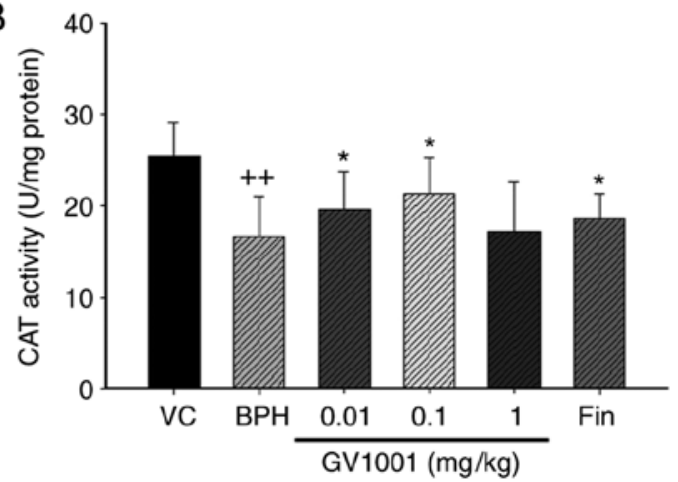

D

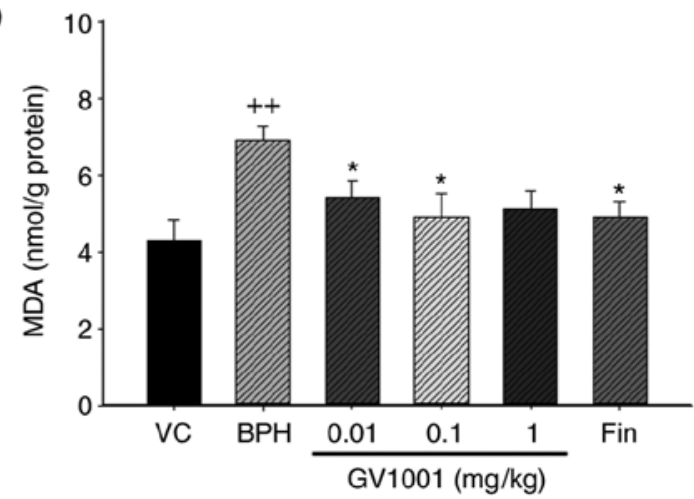

Figure 4. Effect of GV1001 on oxidative stress in the prostates of BPH rats. (A) SOD, (B) CAT, (C) GSH and (D) MDA concentrations were measured in prostate homogenates. Values are presented as mean \pm standard deviation $(n=6) .{ }^{++} \mathrm{P}<0.01$ vs. the VC group, and ${ }^{*} \mathrm{P}<0.05 \mathrm{vs}$. the $\mathrm{BPH}$ group. VC, vehicle control; $\mathrm{BPH}$, benign prostatic hyperplasia; Fin, oral administration of finasteride and s.c. injection of TP (3 mg/kg); GV1001, injection of GV1001 (0.01, 0.1, and $1 \mathrm{mg} / \mathrm{kg})$ and injection of TP (3 mg/kg). SOD, Superoxide dismutase; CAT, catalase, GSH, glutathione; MDA, malondialdehyde; TP, testosterone propionate.

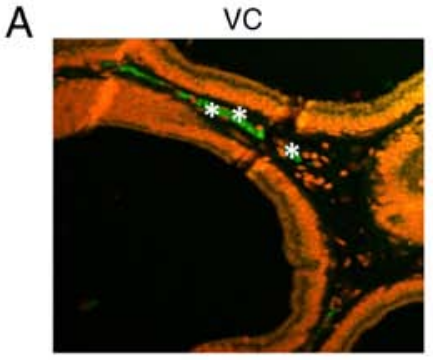

TP+GV1001 $(0.01 \mathrm{mg} / \mathrm{kg})$

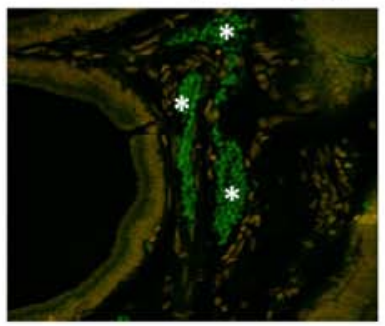

$\mathrm{BPH}: \mathrm{TP}(3 \mathrm{mg} / \mathrm{kg})$

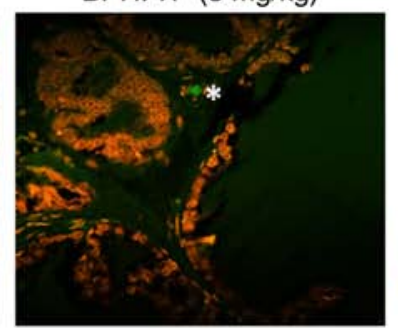

$\mathrm{TP}+\mathrm{GV} 1001(0.1 \mathrm{mg} / \mathrm{kg})$

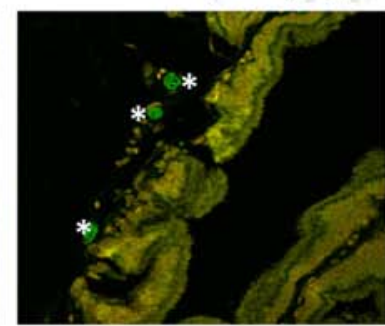

$\mathrm{TP}+\mathrm{Fin}(10 \mathrm{mg} / \mathrm{kg})$

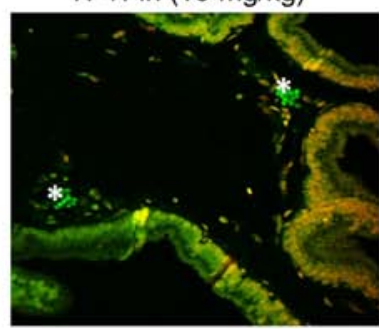

$\mathrm{TP}+\mathrm{GV} 1001(1 \mathrm{mg} / \mathrm{kg})$

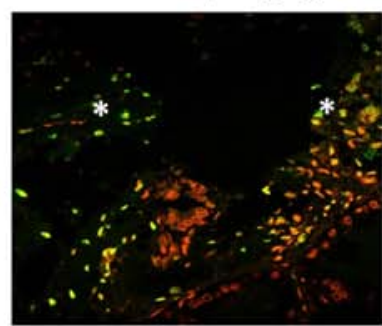

$\mathrm{B}$

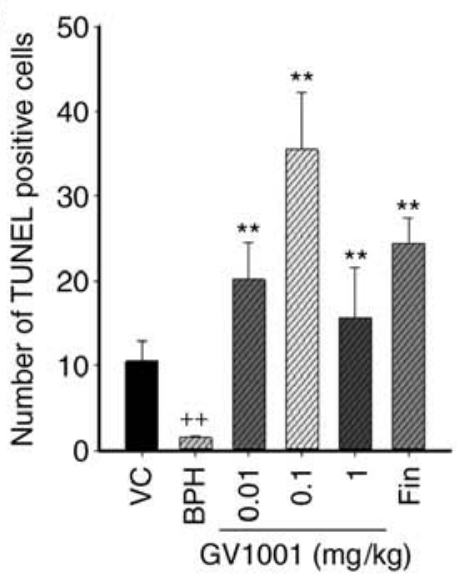

Figure 5. Immunohistochemical analysis of apoptotic cell death in the prostate tissues. Cells undergoing apoptosis were measured using the TUNEL assay. (A) Representative sections are presented for the VC, BPH and GV1001+TP co-treatment groups. Magnification, x50 using Image Hub software. TUNEL-positive cells are indicated by white stars. (B) Mean numbers of positive TUNEL cells in the VC, BPH-induced, finasteride and GV1001-injected groups. Data are presented as mean \pm standard deviation. ${ }^{++} \mathrm{P}<0.01$ vs. the $\mathrm{VC}$ group, and ${ }^{* *} \mathrm{P}<0.01$ vs. the BPH $(\mathrm{TP}, 3 \mathrm{mg} / \mathrm{kg})$ group. TUNEL, terminal deoxynucleotidyl-transferase-mediated dUTP nick end labelling; VC, vehicle control; TP, testosterone propionate; BPH, benign prostatic hyperplasia.

$1 \mathrm{mg} / \mathrm{kg}$ GV1001 groups were $25.67 \pm 2.36,6.58 \pm 2.49$ and $19.42 \pm 4.21$, respectively. Compared with the control and the BPH-induced groups, injection of GV1001 resulted in a significantly higher number of apoptotic cells (Fig. 5). GV1001 treatment increased the proportion of TUNEL-positive cells compared with the BPH-induced groups, demonstrating that the GV1001-mediated inhibition of prostate growth is accompanied by induction of apoptosis. 


\section{Discussion}

The progression of BPH is dependent on several factors including growth factors, adrenergic stimulation and chronic inflammation $(32,33)$. In particular, the cumulative production of ROS and reactive nitrogen species serves a major role in the development of $\mathrm{BPH}$, which is considered a premalignant condition that evolves into prostate diseases $(12,30)$. In clinical studies, chronic oxidative stress and an imbalance in antioxidant activity are more prominent in patients with BPH compared with normal controls $(11,12)$. It has been hypothesized that $\mathrm{BPH}$ is an inflammatory disease, and that inflammation may directly contribute to prostate cell proliferation (34); however, an association between prostatic inflammation and BPH has not been demonstrated conclusively.

GV1001 is an anticancer drug and insulin sensitizer that inhibits glycogenolysis and gluconeogenesis. Although the anti-inflammatory, antipyretic and antioxidant activities of GV1001 have been extensively investigated, to the best of our knowledge there have been no studies examining the effect of GV1001 in the development of BPH. Therefore, the aim of the present study was to investigate the protective effect of GV1001 in a testosterone-induced BPH model, with an emphasis on its roles in antioxidant balance and the inflammatory cascade.

Castration will lead to an imbalance of endogenous hormones; however, injection of exogenous testosterone is an easier method of inducing BPH in animals (35). As this method is also more similar to the pathogenesis of clinical $\mathrm{BPH}$, the protective effects of GV1001 against testosterone-induced BPH in rats was evaluated. Animals in the BPH model group exhibited an increased PI compared with the control animals, which confirmed that the model was successfully established. In the present study, oral administration of finasteride $(10 \mathrm{mg} / \mathrm{kg})$ as a positive control resulted in a significant decrease in relative PW compared to BPH animals. The PW, PI and hormone levels were measured in TP-induced BPH rats. BPH rats exhibited an increased relative PW, elevated testosterone level, prostatic epithelial hyperplasia, and decreased activities of antioxidant enzymes in the prostate. Injection of GV1001 $(0.01$ and $0.1 \mathrm{mg} / \mathrm{kg})$ effectively prevented the development of BPH, as observed by decreased relative PW and PI values, and reduced serum testosterone and DHT levels. Histological changes also indicated that GV1001 $(0.01 \mathrm{mg} / \mathrm{kg})$ injection markedly decreased prostatic epithelial hyperplasia.

Chronic inflammation leads to prostatic cell proliferation by stimulating growth factors through oxidative stress resulting from the endogenous production of ROS. Similarly, an inverse correlation between the activities of antioxidant enzymes and ROS generation, which activates the defense system of the body against the damage caused by oxidative stress, has been demonstrated previously $(36,37)$. Therefore, potentiation of antioxidant enzyme activities may prevent damage to target organs by alleviating oxidative stress. GV1001 treatment significantly increased the activities of the antioxidant enzymes responsible for the decrease of testosterone-induced oxidative damage in prostatic tissue. Therefore, GV1001 may effectively reverse the changes in the activities of antioxidant enzymes during BPH, particularly at doses $>0.1 \mathrm{mg} / \mathrm{kg}$. Previous studies have suggested that tumor necrosis factor (TNF)- $\alpha$ increases levels of intracellular ROS, which may exacerbate inflammatory processes $(36,37)$. The suppressive effects of these antioxidant compounds on the production of these inflammatory mediators are due to their antioxidant activities. Therefore, changes in the activities of prostatic antioxidant enzymes were investigated in the present study.

The present study identified that the activities of SOD and CAT were decreased in the BPH model group, whereas treatment with GV1001 significantly increased the activities of these enzymes. Furthermore, regions of prostatic inflammation will produce free radicals, which attack the plasma membrane and result in lipid peroxidation and MDA production (36). The level of MDA was elevated in the model group compared with the sham group; however, treatment with GV1001 attenuated the increase in MDA. Therefore, GV1001 may successfully reverse the changes in antioxidant enzymes and lipid peroxidation, suggesting that its anti-BPH effects were associated with its antioxidant activities. Furthermore, the apoptotic index measured by TUNEL assay demonstrated low levels of apoptotic cells following induction of BPH by TP. Injection of $0.01,0.1$ and $1 \mathrm{mg} / \mathrm{kg} \mathrm{GV} 1001$ restored normal apoptotic activity, as indicated by an extensive degree of apoptotic body formation. In addition, the data of the present study indicated a lower rate of apoptosis in the rats that received the highest dose of GV1001 $(1 \mathrm{mg} / \mathrm{kg})$, compared with 0.01 and $0.1 \mathrm{mg} / \mathrm{kg} \mathrm{GV1001}$. The increased number of apoptotic bodies within the prostate tissues from rats treated with GV1001 may be considered to be the effect of the induction of apoptosis by the antioxidant activity of GV1001, resulting in suppression of the proliferation of prostate cells. Therefore, $t$ the best of our knowledge, the present study has demonstrated for the first time that GV1001 inhibited prostate growth in vivo by promoting apoptosis in prostatic cells. The results indicated that GV1001 prevented the development of BPH in the testosterone-induced BPH model. This preventive effect is likely due to its potent antioxidant capacity. Therefore, low dose GV1001 $(0.1 \mathrm{mg} / \mathrm{kg})$ may represent a novel complementary therapy and may be used as a novel therapeutic agent to prevent BPH in older men. However, additional experimentation is required to conclusively determine that the antioxidant reaction of GV1001 induced the apoptosis of prostate cells.

\section{Acknowledgements}

We thank Professor Tae Chun Chung (Youngnam University, Republic of Korea) and Professor Kyu-Bong Kim (Dankook University, Republic of Korea) for technical help in the histopathological evaluation of prostate.

\section{Funding}

This research was supported by National Research Foundation of Korea (NRF) Grants funded by the Korean Government (NRF-2015M3A9B6053068).

\section{Availability of data and materials}

All data generated or analyzed during this study are included in this published article. 


\section{Authors' contributions}

HSK and BML conceptualized and designed the study. KSK and HYY acquired the data. SCC, KYL and YMK analyzed and interpreted the data. KSK and HSK drafted the manuscript. KYL, BML and HSK critically revised the manuscript for important intellectual content. KSK and HYY performed the statistical analysis. All the authors read and approved the final manuscript

\section{Ethics approval and consent to participate}

The present study was reviewed and approved by the Sungkyunkwan University Animal Ethics Committee. All experimental procedures were performed in accordance with the Korea Food and Drug Administration (FDA) Guidelines for the Care and Use of Laboratory Animals, and animal handling followed the dictates of the National Animal Welfare Law of Korea. All experimental procedures were performed in accordance with guidelines of the Committee for the Purpose of Control and Supervision of Experiments on Animals of Sungkyunkwan University. The present study was reviewed and approved by the Sungkyunkwan University Animal Ethics Committee.

\section{Patient consent for publication}

Not applicable.

\section{Competing interests}

The authors declare that they have no competing interests.

\section{References}

1. Thorpe A and Neal D: Benign prostatic hyperplasia. Lancet 361: $1359-1367,2003$.

2. Lee SWH, Chan EMC and Lai YK: The global burden of lower urinary tract symptoms suggestive of benign prostatic hyperplasia: A systematic review and meta-analysis. Sci Rep 7: 7984, 2017.

3. Lee YJ, Lee JW, Park J, Seo SI, Chung JI, Yoo TK and Son H: Nationwide incidence and treatment pattern of benign prostatic hyperplasia in Korea. Investig Clin Urol 57: 424-430, 2016.

4. Henry G, Malewska A, Mauck R, Gahan J, Hutchinson R, Torrealba J, Francis F, Roehrborn C and Strand D: Molecular pathogenesis of human prostate basal cell hyperplasia. Prostate 77: 1344-1355, 2017

5. Chughtai B, Forde JC, Thomas DD, Laor L, Hossack T, Woo HH, Te AE and Kaplan SA: Benign prostatic hyperplasia. Nat Rev Dis Primers 2: 16031, 2016.

6. Carson C III and Rittmaster R: The role of dihydrotestosterone in benign prostatic hyperplasia. Urology 61 (4 Suppl 1): S2-S7, 2003.

7. Gandhi J, Weissbart SJ, Smith NL, Kaplan SA, Dagur G, Zumbo A, Joshi G and Khan SA: The impact and management of sexual dysfunction secondary to pharmacological therapy of benign prostatic hyperplasia. Transl Androl Urol 6: 295-304, 2017.

8. Traish AM, Melcangi RC, Bortolato M, Garcia-Segura LM and Zitzmann M: Adverse effects of $5 \alpha$-reductase inhibitors: What do we know, don't know, and need to know? Rev Endocr Metab Disord 16: 177-198, 2015.

9. La Torre A, Giupponi G, Duffy D, Conca A, Cai T and Scardigli A: Sexual dysfunction related to drugs: A critical review. Part V: $\alpha$-blocker and 5-ARI drugs. Pharmacopsychiatry 49: 3-13, 2016.

10. Patel AK and Chappel CR: Benign prostatic hyperplasia, treatment in primary health care. BMJ 333: 535-539, 2006.
11. Srivastava DS and Mittal RD: Free radical injury and antioxidant status in patients with benign prostate hyperplasia and prostate cancer. Indian J Clin Biochem 20: 162-165, 2005.

12. Minciullo PL, Inferrera A, Navarra M, Calapai G, Magno C and Gangemi S: Oxidative stress in benign prostatic hyperplasia: A systematic review. Urol Int 94: 249-254, 2015.

13. Jena AK, Vasisht K, Sharma N, Kaur R, Dhingra MS and Karan M: Amelioration of testosterone induced benign prostatic hyperplasia by Prunus species. J Ethnopharmacol 190: 33-45, 2016.

14. Prasad S, Kalra N and Shukla Y: Modulatory effects of diallyl sulfide against testosterone induced oxidative stress in Swiss albino mice. Asian J Androl 8: 719-723, 2006.

15. Siddiquia IA, Raisuddin S and Shukla A: Protective effects of black tea extract on testosterone induced oxidative damage in prostate. Cancer Lett 227: 125-132, 2005.

16. Parekh MH, Lobel R, Oconnor LJ, Legget RE and Levin RM: Protective effect of vitamin $\mathrm{E}$ on the response of the rabbit bladder to partial outlet obstruction. J Urol 166: 341-346, 2001.

17. Kyte JA: Cancer vaccination with telomerase peptide GV1001. Expert Opin Investig Drugs 18: 687-694, 2009.

18. Shaw VE, Naisbitt DJ, Costello E, Greenhalf W, Park BK, Neoptolemos JP and Middleton GW: Current status of GV1001 and other telomerase vaccination strategies in the treatment of cancer. Expert Rev Vaccines 9: 1007-1016, 2010.

19. Bernhardt SL, Gjertsen MK, Trachsel S, Møller M, Eriksen JA, Meo M, Buanes T and G. Gaudernack G: Telomerase peptide vaccination of patients with non-resectable pancreatic cancer: A dose escalating phase I/II study. Br J Cancer 95: 1474-1482, 2006.

20. Middleton G, Ghaneh P, Costello E, Greenhalf W and Neoptolemos JP: New treatment options for advanced pancreatic cancer. Expert Rev Gastroenterol Hepatol 2: 673-696, 2008.

21. Hunger RE, Kernland Lang K, Markowski CJ, Trachsel S, Møller M, Eriksen JA, Rasmussen AM, Braathen LR and Gaudernack G: Vaccination of patients with cutaneous melanoma with telomerase-specific peptides. Cancer Immunol Immunother 60: 1553-1564, 2011.

22. Brunsvig PF, Kyte JA, Kersten C, Sundstrøm S, Møller M, Nyakas M, Hansen GL, Gaudernack G and Aamdal S: Telomerase peptide vaccination in NSCLC: A phase II trial in stage III patients vaccinated after chemoradiotherapy and an 8-year update on a phase I/II trial. Clin Cancer Res 17: 6847-6857, 2011.

23. Lee YK, Nata'atmaja BS, Kim BH, Pak CS and Heo CY: Protective effect of telomerase-based 16-mer peptide vaccine (GV1001) on inferior epigastric island skin flap survivability in ischaemia-reperfusion injury rat model. J Plast Surg Hand Surg 51: 210-216, 2017.

24. Park HH, Yu HJ, Kim S, Kim G, Choi NY, Lee EH, Lee YJ, Yoon MY, Lee KY and Koh SH: Neural stem cells injured by oxidative stress can be rejuvenated by GV1001, a novel peptide, through scavenging free radicals and enhancing survival signals. Neurotoxicology 55: 131-141, 2016.

25. Ko YJ, Kwon KY, Kum KY, Lee WC, Baek SH, Kang MK, Shon WJ: The anti-inflammatory effect of human telomerase-derived peptide on $P$.gingivalis lipopolysaccharide-induced inflammatory cytokine production and its mechanism in human dental pulp cells. Mediators Inflamm 2015: 385127, 2015.

26. Choi J, Kim H, Kim Y, Jang M, Jeon J, Hwang YI, Shon WJ, Song YW, Kang JS, Lee WJ and Choi J: The anti-inflammatory effect of GV1001 mediated by the downregulation of ENO1-induced pro-inflammatory cytokine production. Immune Netw 15: 291-303, 2015

27. Lee MY, Shin IS, Seo CS, Lee NH, Ha HK, Son JK and Shin HK: Effects of Melandrium firmum methanolic extract on testosterone-induced benign prostatic hyperplasia in Wistar rats. Asian J Androl 14: 320-324, 2012.

28. Steers WD: 5alpha-reductase activity in the prostate. Urology 58 (6 Suppl 1): S17-S24, 2001.

29. Ali MI, Kondreddi HD and Veeresh B: Protective effect of 2-hydroxy-4-methoxy benzoic acid on testosterone induced benign prostatic hyperplasia in Wister rats. Eur J Pharmacol 698: 397-403, 2013.

30. Aydin A, Arsova-Sarafinovska Z, Sayal A, Eken A, Erdem O, Erten K, Ozgök Y and Dimovski A: Oxidative stress and antioxidant status in non-metastatic prostate cancer and benign prostatic hyperplasia. Clin Biochem 39: 176-179, 2006. 
31. Sultan C, Paris F, Terouanne B, Balaguer P, Georget V, Poujol N, Jeandel C, Lumbroso S and Nicolas JC: Disorders linked to insufficient androgen action in male children. Hum Reprod Update 7: 314-322, 2001.

32. Culig Z, Hobisch A, Cronauer MV, Radmayr C, Hittmair A, Zhang J, Thurnher M, Bartsch G and Klocker H: Regulation of prostatic growth and function by peptide growth factors. Prostate 28: 392-405, 1996.

33. Jacobsen SJ, Girman CJ and Lieber MM: Natural history of benign prostatic hyperplasia. Urology 58 (6 Suppl 1): S5-S16, 2001 .

34. Bostanci Y, Kazzazi A, Momtahen S, Laze J and Djavan B: Correlation between benign prostatic hyperplasia and inflammation. Curr Opin Urol 23: 5-10, 2013.
35. Chung LW, Matsuura J and Runner MN: Tissue interactions and prostatic growth. I. Induction of adult mouse prostatic hyperplasia by fetal urogenital sinus implants. Biol Reprod 31: 155-163, 1984.

36. Vral A, Magri V, Montanari E, Gazzano G, Gourvas V, Marras E and Perletti G: Topographic and quantitative relationship between prostate inflammation, proliferative inflammatory atrophy and low-grade prostate intraepithelial neoplasia: A biopsy study in chronic prostatitis patients. Int J Oncol 41: 1950-1958, 2012.

37. Gao M, Ding H, Zhong G, Lu J, Wang H, Li Q and Wang Z: The effects of transrectal radiofrequency hyperthermia on patients with chronic prostatitis and the changes of MDA, NO, SOD, and $\mathrm{Zn}$ levels in pretreatment and posttreatment. Urology 79: 391-396, 2012. 